\title{
Isolation and Characterization of BpL1, a Broad Acting Lytic Bacteriophage against Brucella
}

\author{
Vimlesh Gupta and Hari Mohan Saxena*
}

\author{
Department of Veterinary Microbiology, College of Veterinary Science, Guru Angad Dev \\ Veterinary and Animal Sciences University, Ludhiana - 141004, Punjab, India \\ *Corresponding author
}

\section{A B S T R A C T}

In view of the ever increasing antimicrobial resistance, bacteriophages are promising alternatives for treatment of bacterial infections. Brucellosis is an important zoonotic

Keywords

Brucella,

Bacteriophage,

Brucellaphage,

Phage isolation.

Article Info

Accepted:

20 September 2017

Available Online:

10 November 2017 disease for which currently there is no satisfactory treatment. We have isolated a new broad acting lytic brucellaphage (BpL1) from the sewage of a dairy farm. The phage lysed all the 12 Brucella abortus field isolates, B. abortus strain 99 and Brucella melitensis but did not lyse any of the heterologous species tested viz. Staphylococcus aureus, Pasteurella multocida, Escherichia coli, and Salmonella species. Streaking the lysis plaques on Brucella lawn gave clear lytic zones along the streak lines. The plaques were circular with a diameter of $0.5-3.0 \mathrm{~mm}$. At a concentration of $10^{-4}$ the phage count was $4.5 \times 10^{6}$ plaques per $\mathrm{ml}$. It was a tailed phage with icosahedral head $(62.2 \mathrm{~nm}$ in diameter and 73.71 $\mathrm{nm}$ in length), and the head to tail length was $229.21 \mathrm{~nm}$. The phage belonged to the order Caudovirales and family Siphoviridae. It was inactivated within one hour at $55^{\circ} \mathrm{C}$ and within $4 \mathrm{~h}$ at $-20^{\circ} \mathrm{C}$. Treatment at $\mathrm{pH} 2$ for $4 \mathrm{~h}$ and at $\mathrm{pH} 4$ for $12 \mathrm{~h}$ inactivated it. It was also inactivated after $4 \mathrm{~h}$ exposure to sunlight, and within $4 \mathrm{~min}$. by UV light. Chloroform and Sodium Dodecyl Sulfate inactivated it within $15 \mathrm{~min}$. Lysozyme inactivated it within 1 hour whereas RNase treatment did not affect its activity.

\section{Introduction}

Brucellosis is a highly contagious and important zoonotic disease caused by different species of the genus Brucella. The Brucella organisms are pathogenic for a wide variety of animals such as swine, cattle, goat, sheep, and dogs and also for humans (Mathur et al., 2007). In animals, brucellosis mainly affects reproduction and fertility, reduces the survival of newborns, and diminishes milk yield. Outbreak of Brucellosis in animals is characterized by abortions during the last trimester of gestation. Brucellosis is endemic in India and is prevalent in all parts of the country. Currently, no effective and affordable treatment is available for Brucellosis in large animals. Antibiotic resistance has been detected in Brucella organisms also (Gupta and Saxena, 2017). The widely used S-19 vaccine has not been successful in controlling Bucellosis since infection in some vaccinated animals has also been observed (Mohan et al., 2016). A bacteriophage is a virus that specifically infects and lyses its host bacterium. This unique characteristic can be exploited for therapy of infections due to antibiotic 
resistant bacteria. We report here the isolation of a new Brucellaphage from the habitat of Brucella infected animals i.e. sheds of infected cattle.

\section{Materials and Methods}

\section{Isolation, identification characterization of Brucella abortus}

and

Brucella abortus vaccine strain S19, Brucella abortus S99, B. melitensis Rev1 and $B$. melitensis were grown on Brucella selective agar (HiMedia) and incubated at $37^{\circ} \mathrm{C}$ aerobically. B. abortus from field samples were isolated on Brucella selective agar (Gupta and Saxena, 2017). Samples comprising of aborted foetal stomach contents, placenta and cotyledons and vaginal and uterine secretions from cattle and buffaloes with a history of abortions were collected and were subjected to isolation. Brucella isolates were identified on the basis of cultural, morphological and biochemical characteristics. DNA extraction was done as per the standard protocols of Sambrook and Russell (2001). Molecular characterization of the field isolates was done by polymerase chain reaction (PCR) as per the method of Romero et al., (1995).

\section{Isolation of bacteriophage against Brucella abortus}

Agar overlay technique was used to isolate bacteriophage against Brucella abortus (Adams 1959, Chilamban et al., 2004). A set of available heterologous species of bacteria of veterinary importance viz. Pasteurella multocida B: 2, E.coli, Staphylococcus, Streptococcus, Salmonella Dublin, Micrococcus and Pseudomonas species were used.

A total of seven sewage samples were collected from the drain of a dairy farm in
Ludhiana at different times and processed for the isolation of phage. In brief, to the $50 \mathrm{ml}$ double strength NZCYM broth (Life Technologies) $40 \mathrm{ml}$ sewage supernatant and $10 \mathrm{ml}$ of broth culture of $B$. abortus in exponential growth were added and incubated on rotary shaker for 10 days at $37^{\circ} \mathrm{C}$. Out of this incubated sewage containing bacteria cocktail, $10 \mathrm{ml}$ of supernatant was taken every day and centrifuged at $8000 \mathrm{~g}$ for 15 min. to collect the supernatant which was passed through $0.22 \mu \mathrm{m}$ PVDF filter (Axiva) and the filtrate was aseptically collected and stored at $4^{\circ} \mathrm{C}$ till further use and was designated as Bacteria Free Filtrate (BFF). Equal quantities $(100 \mu \mathrm{l})$ of $\mathrm{BFF}$ and overnight broth culture of $B$. abortus were mixed in $0.75 \%$ NZCYM agar (maintained at $45^{\circ} \mathrm{C}$ in a dry bath) and was spread evenly over $1.5 \%$ NZCYM agar containing BSM agar. The soft agar was allowed to solidify and the plates were incubated at $37^{\circ} \mathrm{C}$ for 48 $72 \mathrm{~h}$ to observe plaques.

\section{Elution of brucellaphage}

The plaques were picked using a straight wire loop and were streaked horizontally and then vertically on a hardened NZCYM + BSM plate overlaid with semisolid NZCYM agar containing the indicator strain. The plate was incubated at $37^{\circ} \mathrm{C}$ for $18 \mathrm{~h}$ to observe plaques along the lines. SM buffer $(2 \mathrm{ml})$ was poured over the agar and the agar was disturbed with the wire loop to release the phages from the semisolid agar. This SM buffer was then collected and centrifuged at $5000 \mathrm{~g}$ to remove the agar and then the supernatant was filtered through $0.22 \mu \mathrm{m}$ filters to remove the bacteria and elute the phage in SM buffer.

Effect of varied temperatures on the brucellaphage

$100 \mu \mathrm{l}$ of brucellaphage $\left(10^{6} \mathrm{pfu} / \mathrm{ml}\right)$ was subjected to temperatures of $-20^{\circ} \mathrm{C}, 4^{\circ} \mathrm{C}$, 
$37^{\circ} \mathrm{C}, 50^{\circ} \mathrm{C}, 70^{\circ} \mathrm{C}$ and $100^{\circ} \mathrm{C}$ for a period of 20 min. Freshly grown Brucella abortus S19 culture $(200 \mu \mathrm{l})$ was added in cooled molten semisolid NZCYM and plated on $\mathrm{BSM}+\mathrm{NZCYM}$ plates. These plates were incubated aerobically at $37^{\circ} \mathrm{C}$ for 48 to $72 \mathrm{~h}$. Any change in pfu was observed.

\section{Effect of light on the brucellaphage}

$100 \mu \mathrm{l}$ of brucellaphage $\left(10^{6} \mathrm{pfu} / \mathrm{ml}\right)$ was subjected to normal fluorescent tube light, sunlight and UV light for a period of $15 \mathrm{~min}$ to 90 min. $200 \mu \mathrm{l}$ of freshly grown Brucella abortus S19 culture was added in cooled molten semisolid NZCYM and plated on BSM+NZCYM plates. The plates were incubated aerobically at $37^{\circ} \mathrm{C}$ for $48-72 \mathrm{~h}$. It was observed for any change in pfu.

\section{Effect of enzymes on the brucellaphage}

$100 \mu \mathrm{l}$ of brucellaphage $\left(10^{6} \mathrm{pfu} / \mathrm{ml}\right)$ and 100 $\mu \mathrm{l}$ of enzymes viz. proteinase $\mathrm{K}(20 \mathrm{mg} / \mathrm{ml})$, trypsin $(250 \mu \mathrm{g} / \mathrm{ml})$, lysozyme $(20 \mathrm{mg} / \mathrm{ml})$ and RNAse $(10 \mathrm{mg} / \mathrm{ml})$ were incubated for $15 \mathrm{~min}$. $200 \mu 1$ of freshly grown Brucella abortus S19 culture was added in cooled molten semisolid NZCYM and plated on BSM+NZCYM plates. These plates were incubated aerobically at $37^{\circ} \mathrm{C}$ for 48 to $72 \mathrm{~h}$. Any change in pfu was noted down.

Effect of SDS, normal saline and EDTA on the brucellaphage

$100 \mu \mathrm{l}$ of brucellaphage $\left(10^{6} \mathrm{pfu} / \mathrm{ml}\right)$ was subjected to treatment with equal volume of $10 \%$ Sodium dodecyl Sulfate (SDS), Normal Saline Solution (NSS) and EDTA (0.01M) for a period of $15 \mathrm{~min}$ to $3 \mathrm{~h}$. Any change in pfu was observed by adding $200 \mu \mathrm{l}$ of freshly grown Brucella abortus S19 culture in cooled molten semisolid NZCYM and plated on BSM+NZCYM plates. These plates were incubated aerobically at $37^{\circ} \mathrm{C}$ for 48 to $72 \mathrm{~h}$.
Effect of varied pH on the survivability of bacteriophage

$100 \mu \mathrm{l}$ of brucellaphage $\left(10^{6} \mathrm{pfu} / \mathrm{ml}\right)$ was observed for the change in pfu count in different $\mathrm{pH}$ ranges of $3,5,7$ and 9 for periods of $30 \mathrm{~min}$ and $60 \mathrm{~min}$ exposure time. Any change in pfu was observed by adding $200 \mu 1$ of freshly grown Brucella culture in cooled molten semisolid NZCYM and plated on BSM+NZCYM plates. These plates were incubated aerobically at $37^{\circ} \mathrm{C}$ for 48 to $72 \mathrm{~h}$.

\section{Results and Discussion}

\section{Isolation of brucellaphage}

Out of the total 36 sewage samples, brucellaphage could be isolated from one sample. Streaking the plaques on Brucella lawn gave clear zones along the streak lines (Fig. 1).

At a concentration of $10^{-4}$ the phage count was $4.5 \times 10^{6}$ plaques per $\mathrm{ml}$. We propose the name "Brucellaphage Ludhiana 1 (BpL1)" for this new phage.

\section{Heterogeneity test for brucellaphage}

The isolated brucellaphage lysed all the 12 Brucella abortus field isolates, B. abortus strain 99 and Brucella melitensis (procured from IVRI, Izatnagar) at MIC 1:50 but did not lyse any of the heterologous species tested viz. Staphylococcus aureus, Salmonella species, Escherichia coli, and Pasteurella multocida.

\section{Morphological characterization of brucellaphage}

\section{Plaque morphology}

The observed plaques were circular (Fig. 2) with a diameter of 0.5-3.0 mm. 


\section{Phage morphology}

The brucellaphage isolated in the present study was a tailed phage with icosahedral head $(62.2 \mathrm{~nm}$ in diameter and $73.71 \mathrm{~nm}$ in length), and the head to tail length was 229.21 nm (Fig. 3).

\section{Physicochemical characterization of the} brucellaphage

\section{Effect of temperature}

The effect of temperature on the survivability of brucellaphage was studied. The phage titre gradually decreased from $4.5 \times 10^{6}$ to $2.0 \times$ $10^{6} \mathrm{pfu} / \mathrm{ml}$ within $48 \mathrm{~h}$ at $0^{\circ} \mathrm{C}$. Temperature treatments of $-20^{\circ} \mathrm{C}$ completely inactivated the phage within $4 \mathrm{~h}$ and treatment at $55^{\circ} \mathrm{C}$ completely inactivated the phage within 1 hour (Table 1, Fig. 4).

\section{Effect of pH on brucellaphage}

Exposures to various $\mathrm{pH}(\mathrm{pH} 2,4,6,8,10)$ were given to the brucellaphage to determine its survivability. The phage was inactivated at $\mathrm{pH} 2$ within $4 \mathrm{~h}$, and at $\mathrm{pH} 4$ within $12 \mathrm{~h}$. However the phage survived up to $24 \mathrm{~h}$ at $\mathrm{pH}$ 6 .The phage number gradually decreased from $4.5 \times 10^{6}$ to $2.0 \times 10^{6}$ within $48 \mathrm{~h}$ at $\mathrm{pH} 8$. It decreased to 0 within $24 \mathrm{~h}$ at $\mathrm{pH} 10$ (Table 2, Fig. 5).

\section{Effect of sunlight}

When the brucellaphage was exposed to sunlight, the phage titre decreased gradually from $4.5 \times 10^{6}$ to $0.2 \times 10^{6}$ within $3 \mathrm{~h}$ and was completely inactivated after $4 \mathrm{~h}$ (Table 3 , Fig. $6)$.

\section{Effect of UV light}

Exposure to UV light was found to have a drastic effect on phage survivability. The phage gets completely inactivated within 4 min. (Table 4, Fig. 7).

\section{Chemical characterization of phage}

\section{Effect of chloroform (10\%) on phage}

The treatment of phage with $10 \%$ chloroform completely inactivated it within $15 \mathrm{~min}$. at $37^{\circ} \mathrm{C}$ (Table 5, Fig. 8).

\section{Effect of SDS on phage}

The effect of sodium dodecyl sulphate (SDS) treatment on activity of phage was studied. It was found that both $1 \%$ and $0.1 \%$ concentrations of SDS completely inactivated the phage within $15 \mathrm{~min}$. at $37^{\circ} \mathrm{C}$ (Table 6 , Fig. 9).

\section{Effect of enzymes on phage activity:}

\section{Effect of lysozyme}

Lysozyme at a concentration of $20 \mathrm{mg} / \mathrm{ml}$ completely inactivated the phage within one hour (Table 7, Fig. 10).

\section{Effect of RNase on phage}

No detectable change was found on treatment of phage with RNase for $120 \mathrm{~min}$. (Table 8, Fig. 11). According to Ackermann (2007) such types of phages belong to the order Caudovirales and family Siphoviridae.

We propose to name it as "Brucellaphage Ludhiana 1 (BpL1)". Cai-Zhong et al., (2009) classified $\mathrm{Tb}$ (Tbilisi), as a member of the Podoviridae family with icosahedral capsids (57 $\pm 2 \mathrm{~nm}$ diameter) and short tails $(32 \pm 3$ nm long). Chachra et al., (2012) reported that electron microscopic studies of the brucellaphage revealed it to be an elementary body measuring approximately $65 \mathrm{~nm}$ with rounded head and a very short tail. 
Table.1 Effect of temperature on survivability of brucellaphage

\begin{tabular}{|c|c|c|c|c|}
\hline S. No & Time of incubation & $\mathbf{0}^{\mathbf{0}} \mathbf{C}$ & $\mathbf{- 2 0}^{\mathbf{0}} \mathbf{C}$ & $\mathbf{5 5}^{\mathbf{0}} \mathbf{C}$ \\
\hline 1 & $0 \mathrm{~min}$ & $4.5 \times 10^{6}$ & $4.5 \times 10^{6}$ & $4.5 \times 10^{6}$ \\
\hline 2 & $30 \mathrm{~min}$ & $4.0 \times 10^{6}$ & $1.5 \times 10^{6}$ & $0.3 \times 10^{6}$ \\
\hline 3 & $1 \mathrm{hr}$. & $3.6 \times 10^{6}$ & $0.2 \times 10^{6}$ & \\
\cline { 1 - 3 } & $4 \mathrm{hr}$. & $3.0 \times 10^{6}$ & & \\
\cline { 1 - 3 } & $12 \mathrm{hr}$. & $2.5 \times 10^{6}$ & & \\
\cline { 1 - 3 } 6. & $24 \mathrm{hr}$. & $2.0 \times 10^{6}$ & & \\
\hline 7. & $48 \mathrm{hr}$. & $2.0 \times 10^{6}$ & & \\
\hline
\end{tabular}

Table.2 Effect of $\mathrm{pH}$ on brucellaphage survivability

\begin{tabular}{|c|c|c|c|c|c|c|}
\hline S. No & Time duration & $\mathbf{p H ~ 2}$ & $\mathbf{p H ~ 4}$ & $\mathbf{p H ~ 6}$ & $\mathbf{p H ~ 8}$ & $\mathbf{p H ~ 1 0}$ \\
\hline 1 & $0 \mathrm{~min}$ & $4.5 \times 10^{6}$ & $4.5 \times 10^{6}$ & $4.5 \times 10^{6}$ & $4.5 \times 10^{6}$ & $4.5 \times 10^{6}$ \\
\hline 2 & $30 \mathrm{~min}$ & $0.3 \times 10^{6}$ & $0.5 \times 10^{6}$ & $0.8 \times 10^{6}$ & $3.5 \times 10^{6}$ & $2.5 \times 10^{6}$ \\
\hline 3 & $1 \mathrm{hr}$. & $0.1 \times 10^{6}$ & $0.5 \times 10^{6}$ & $0.5 \times 10^{6}$ & $3.2 \times 10^{6}$ & $1.5 \times 10^{6}$ \\
\hline 4 & $4 \mathrm{hr}$. & & $0.1 \times 10^{6}$ & $0.2 \times 10^{6}$ & $3.2 \times 10^{6}$ & $1.0 \times 10^{6}$ \\
\hline 5. & $12 \mathrm{hr}$. & & & $0.1 \times 10^{6}$ & $2.5 \times 10^{6}$ & $0.2 \times 10^{6}$ \\
\hline 6. & $24 \mathrm{hr}$. & & & $0.1 \times 10^{6}$ & $2.4 \times 10^{6}$ & \\
\cline { 1 - 1 } & & & & $2.0 \times 10^{6}$ & \\
\hline 7 & $48 \mathrm{hr}$. & & & & \\
\hline
\end{tabular}

Table.3 Effect of sunlight on brucellaphage survival

\begin{tabular}{|c|c|c|}
\hline S. No. & Duration of exposure & Phage count (Pfu/ml) \\
\hline 1 & $0 \mathrm{~min}$ & $4.5 \times 10^{6}$ \\
\hline 2 & $30 \mathrm{~min}$ & $2.9 \times 10^{6}$ \\
\hline 3 & $1 \mathrm{hr}$. & $1.8 \times 10^{6}$ \\
\hline 4 & $3 \mathrm{hr}$. & $0.2 \times 10^{6}$ \\
\hline 5 & $4 \mathrm{hr}$. & - \\
\hline 6 & $12 \mathrm{hr}$. & \\
\hline
\end{tabular}

Table.4 Effect of UV light on brucellaphage

\begin{tabular}{|c|c|c|}
\hline S. No. & Time duration of exposure & Phage count $(\mathbf{P f u} / \mathbf{m l})$ \\
\hline 1 & $0 \mathrm{~min}$ & $4.5 \times 10^{6}$ \\
\hline 2 & $2 \mathrm{~min}$ & $0.3 \times 10^{6}$ \\
\hline 3 & $4 \mathrm{~min}$ & \\
\hline
\end{tabular}

Table.5 Effect of chloroform on phage survival

\begin{tabular}{|c|c|c|}
\hline S. No. & Time interval & Pfu/ml \\
\hline 1 & $0 \mathrm{~min}$ & $3.9 \times 10^{6}$ \\
\hline 2 & $10 \mathrm{~min}$ & $0.2 \times 10^{3}$ \\
\hline 3 & $15 \mathrm{~min}$ & \\
\hline
\end{tabular}


Table.6 Effect of SDS treatment on phage

\begin{tabular}{|c|c|c|c|}
\hline S. No & Time interval & Pfu/ml in 0.1\% SDS & Pfu/ml in 1.0\% SDS \\
\hline 1 & $0 \mathrm{~min}$ & $4.4 \times 10^{6}$ & $4.2 \times 10^{6}$ \\
\hline 2 & $10 \mathrm{~min}$ & $0.3 \times 10^{6}$ & $0.1 \times 10^{6}$ \\
\hline 3 & $15 \mathrm{~min}$ & - & - \\
\hline
\end{tabular}

Table.7 Effect of lysozyme on phage

\begin{tabular}{|l|l|l|}
\hline S. No & Duration of exposure & Phage count $(\mathbf{P f u} / \mathbf{m l})$ \\
\hline 1 & $0 \mathrm{~min}$ & $3.5 \times 10^{6}$ \\
\hline 2 & $10 \mathrm{~min}$ & $1.0 \times 10^{6}$ \\
\hline 3 & $30 \mathrm{~min}$ & $0.1 \times 10^{6}$ \\
\hline 4 & $60 \mathrm{~min}$ & - \\
\hline
\end{tabular}

Table.8 Effect of RNase on phage

\begin{tabular}{|c|c|c|}
\hline S. No & Duration of exposure & Phage count (Pfu/ml) \\
\hline 1 & $0 \mathrm{~min}$ & $4.4 \times 10^{6}$ \\
\hline 2 & $10 \mathrm{~min}$ & $4.2 \times 10^{6}$ \\
\hline 3 & $30 \mathrm{~min}$ & $3.9 \times 10^{6}$ \\
\hline 4 & $60 \mathrm{~min}$ & $3.5 \times 10^{6}$ \\
\hline 5 & $120 \mathrm{~min}$ & $2.5 \times 10^{6}$ \\
\hline
\end{tabular}

Fig.1 Lytic zones along the streaking lines of BpL1 on Brucella lawn

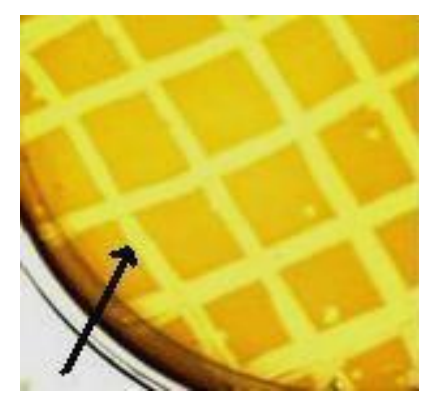

Fig.2 Circular plaques caused by BpL1 on Brucella abortus S19 lawn

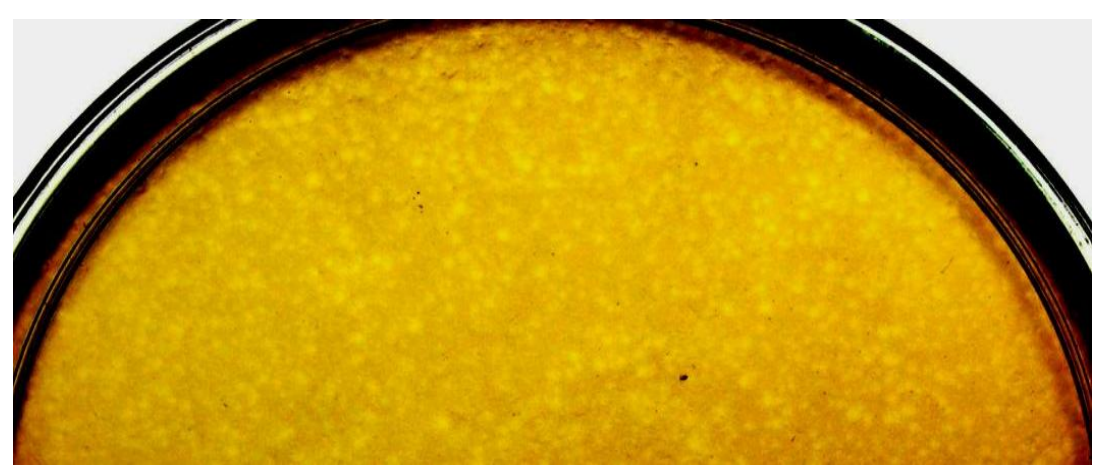


Fig.3 Electron micrograph of brucellaphage BpL1

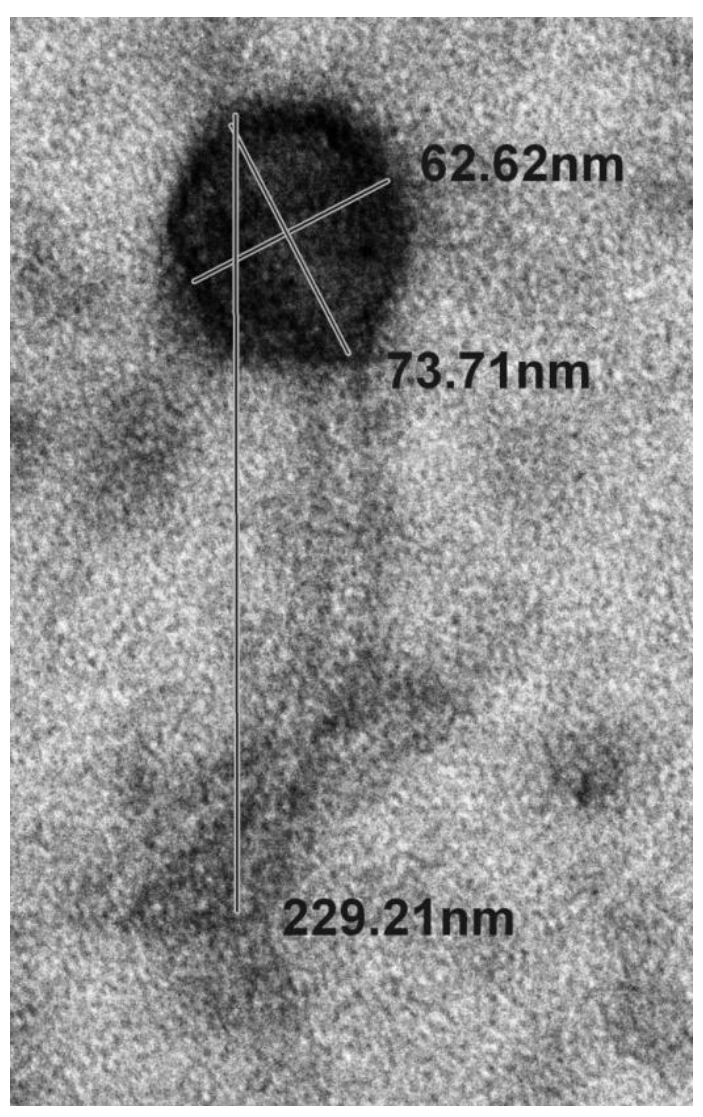

Fig.4 Effect of temperature on phage survival

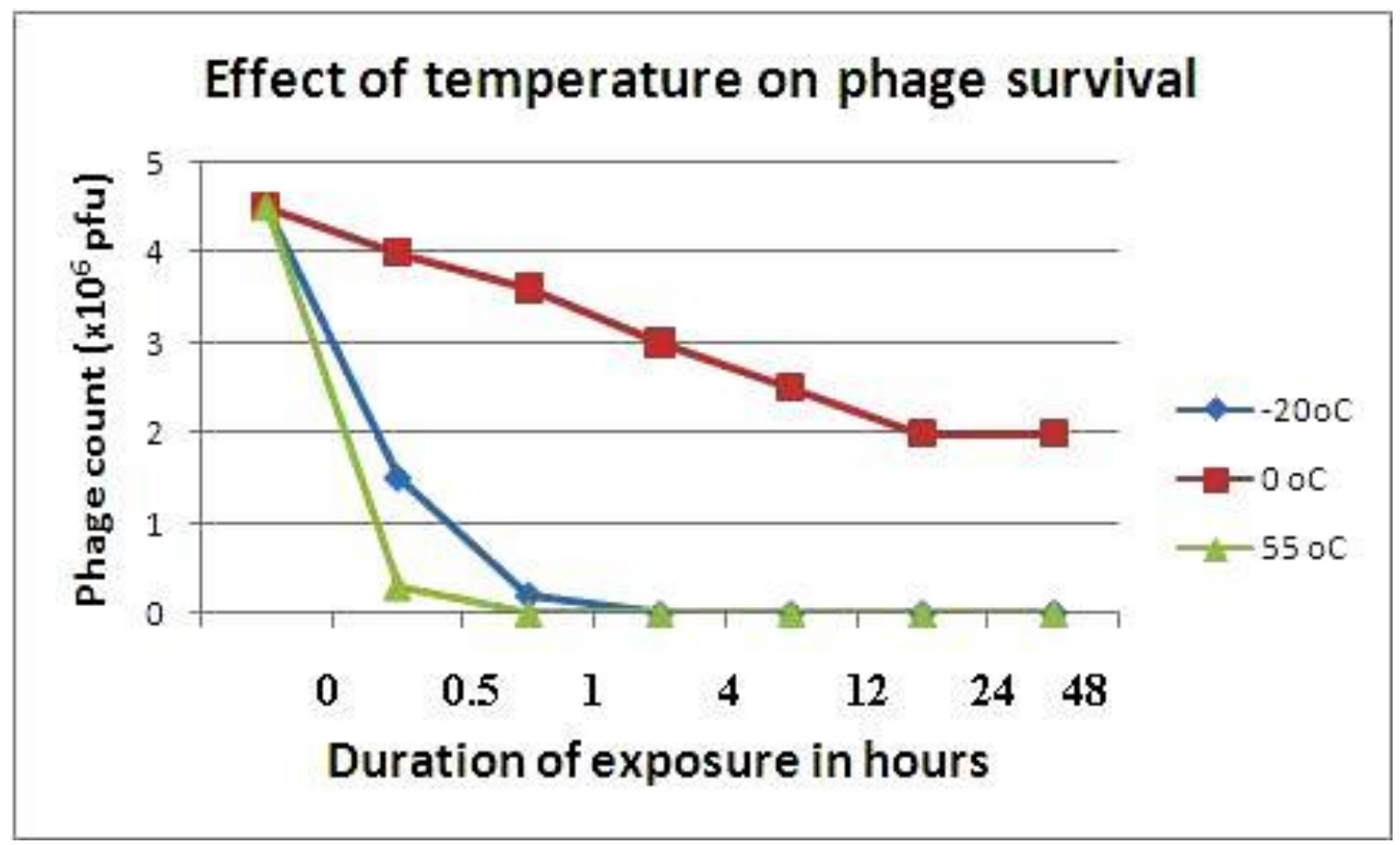


Fig.5 Effect of pH on phage survival

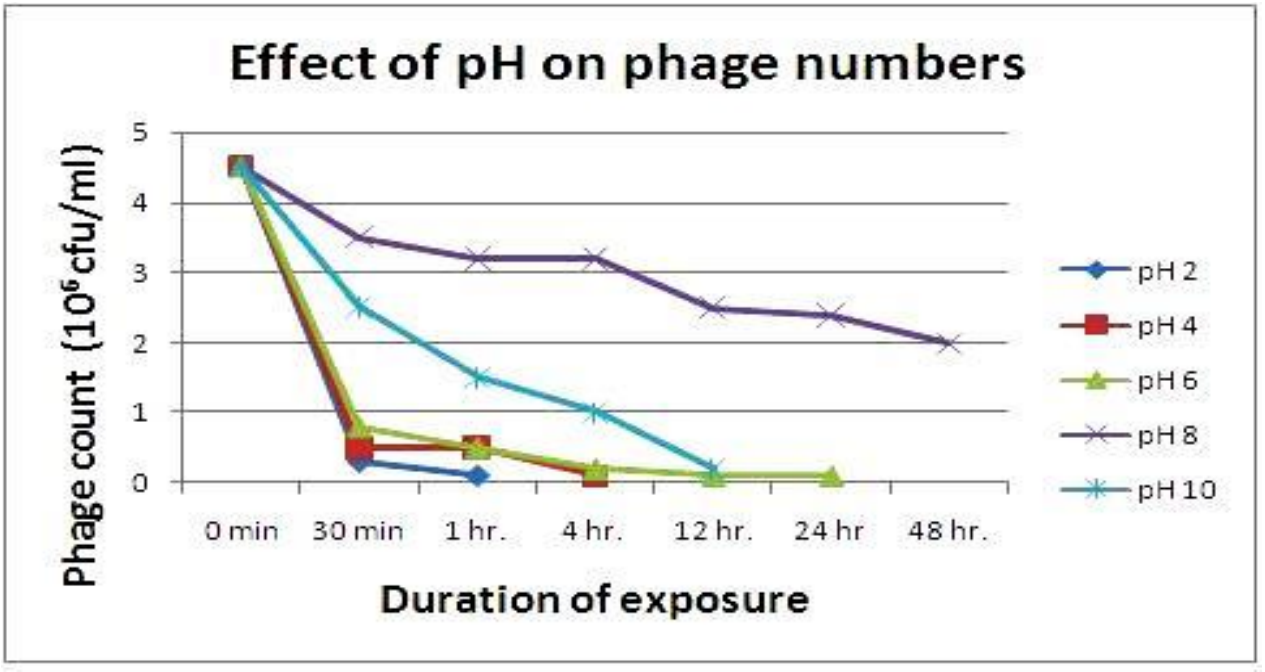

Fig.6 Effect of exposure to sunlight on brucellaphage survivability

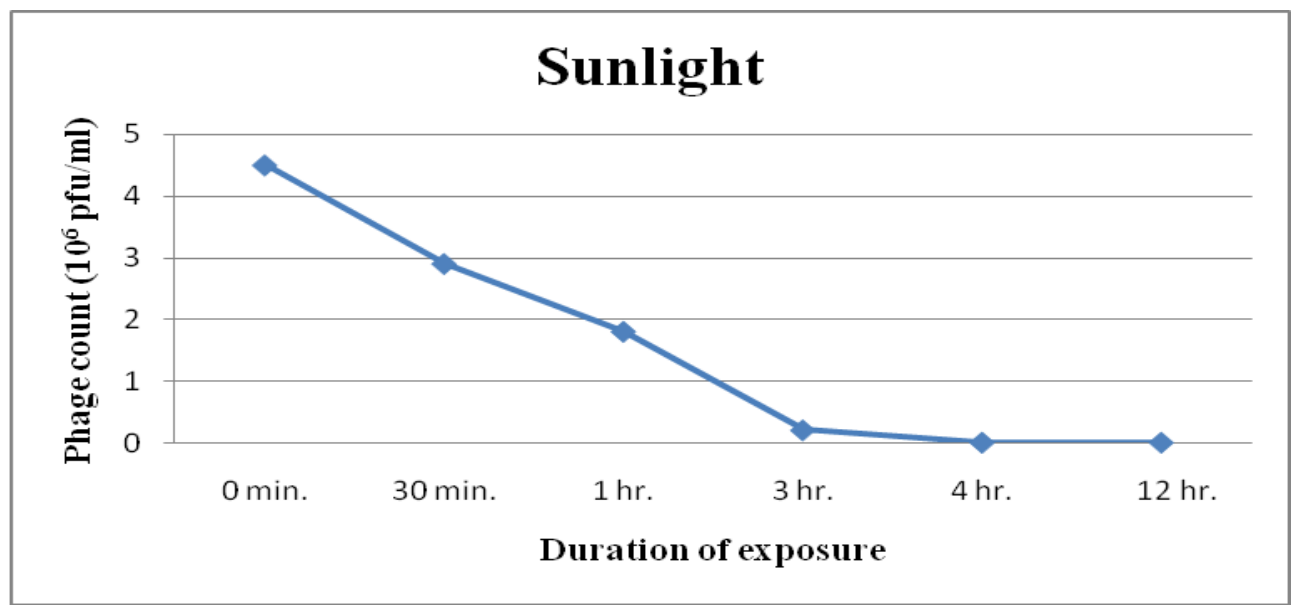

Fig.7 Effect of exposure to UV light on phage survival

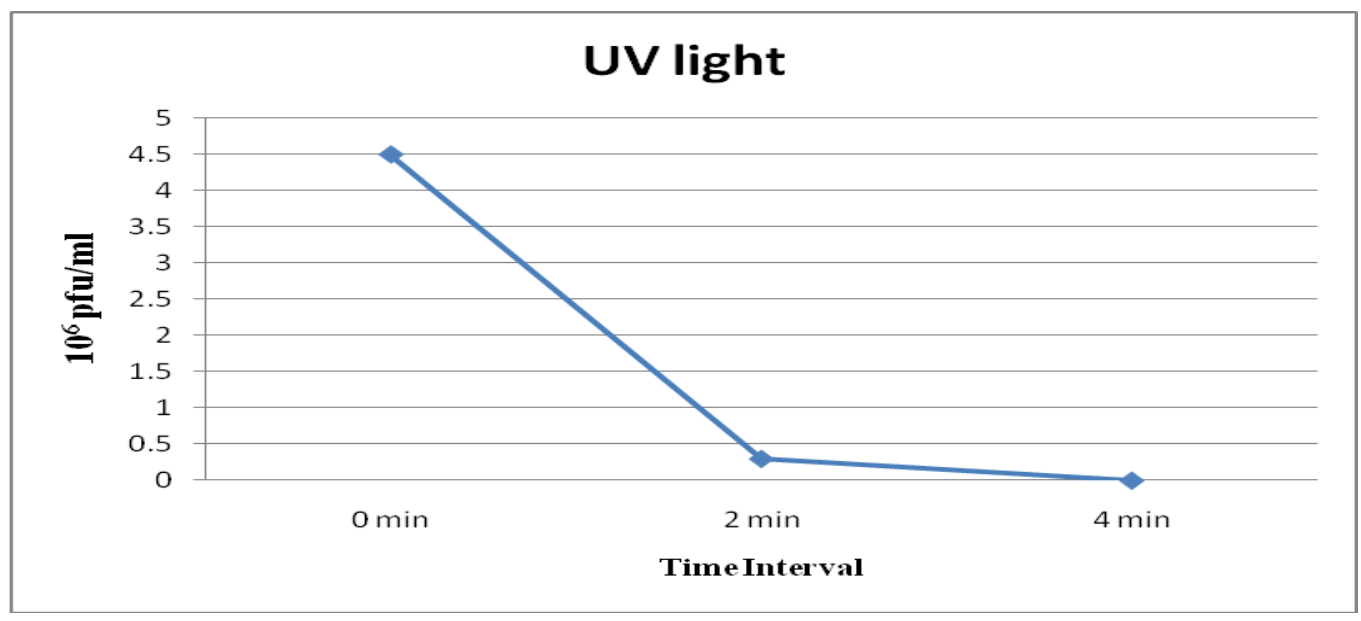


Fig.8 Effect of chloroform on phage survival

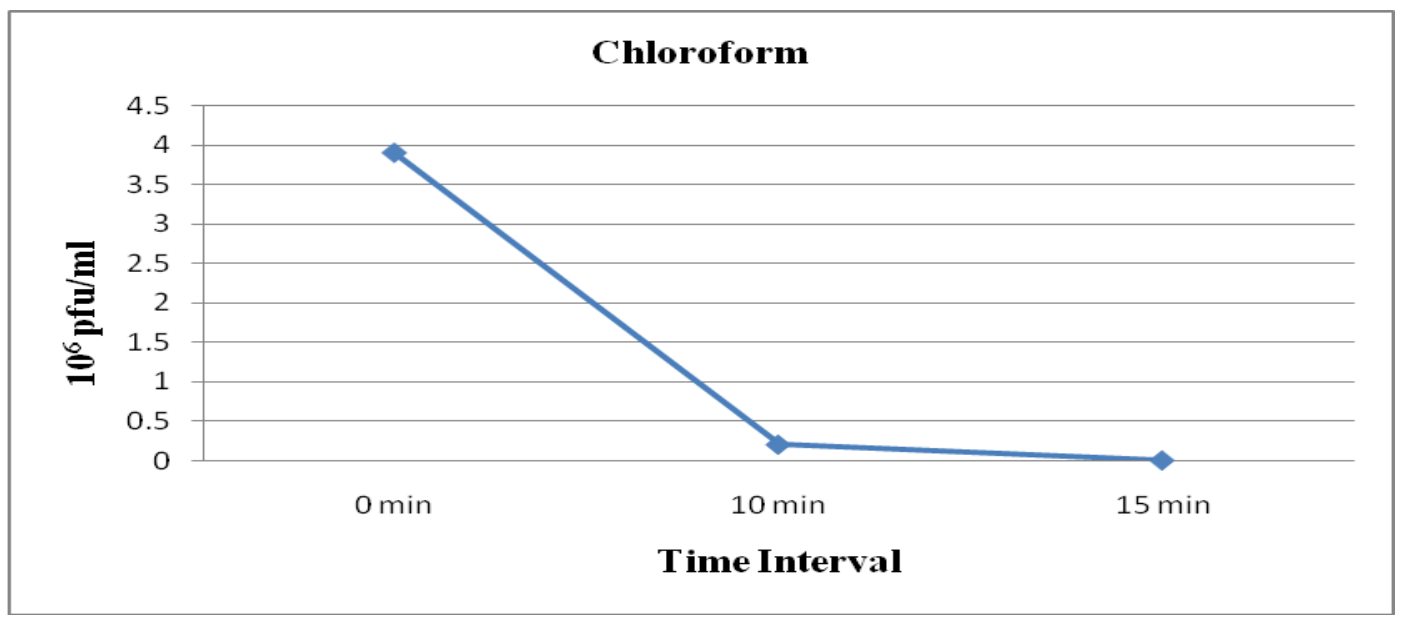

Fig.9 Effect of SDS on phage

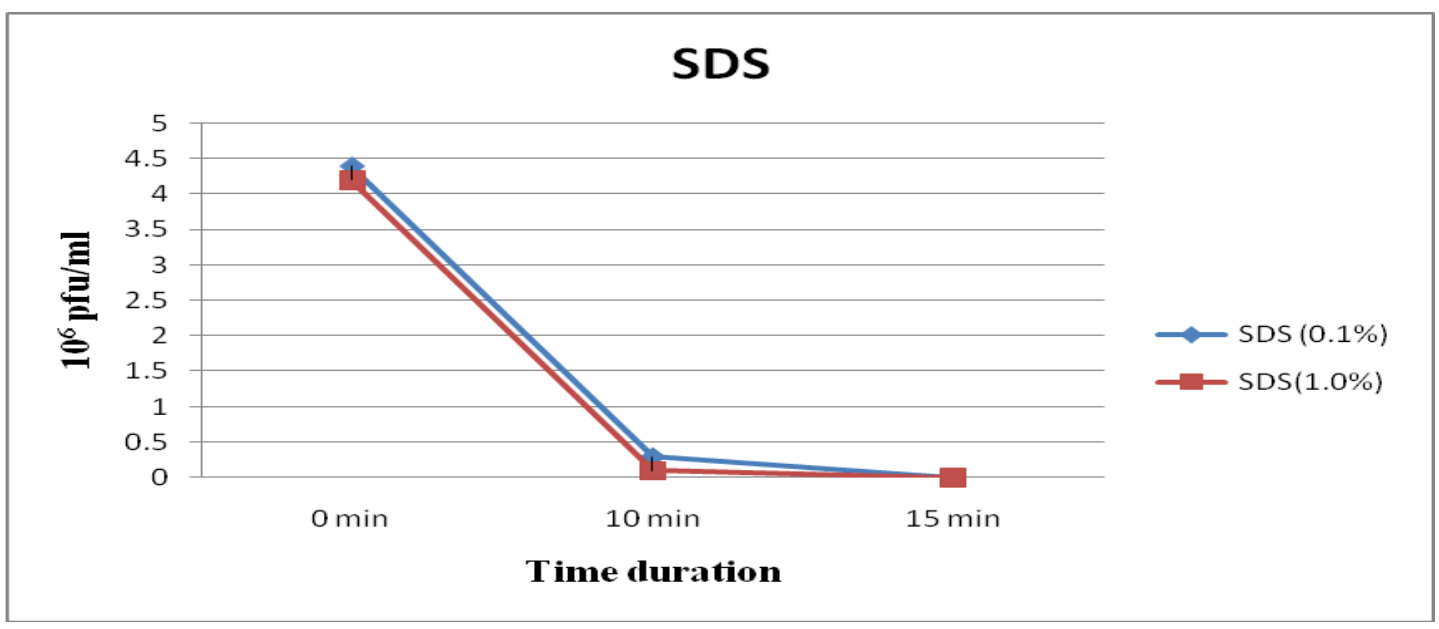

Fig.10 Effect of lysozyme on phage

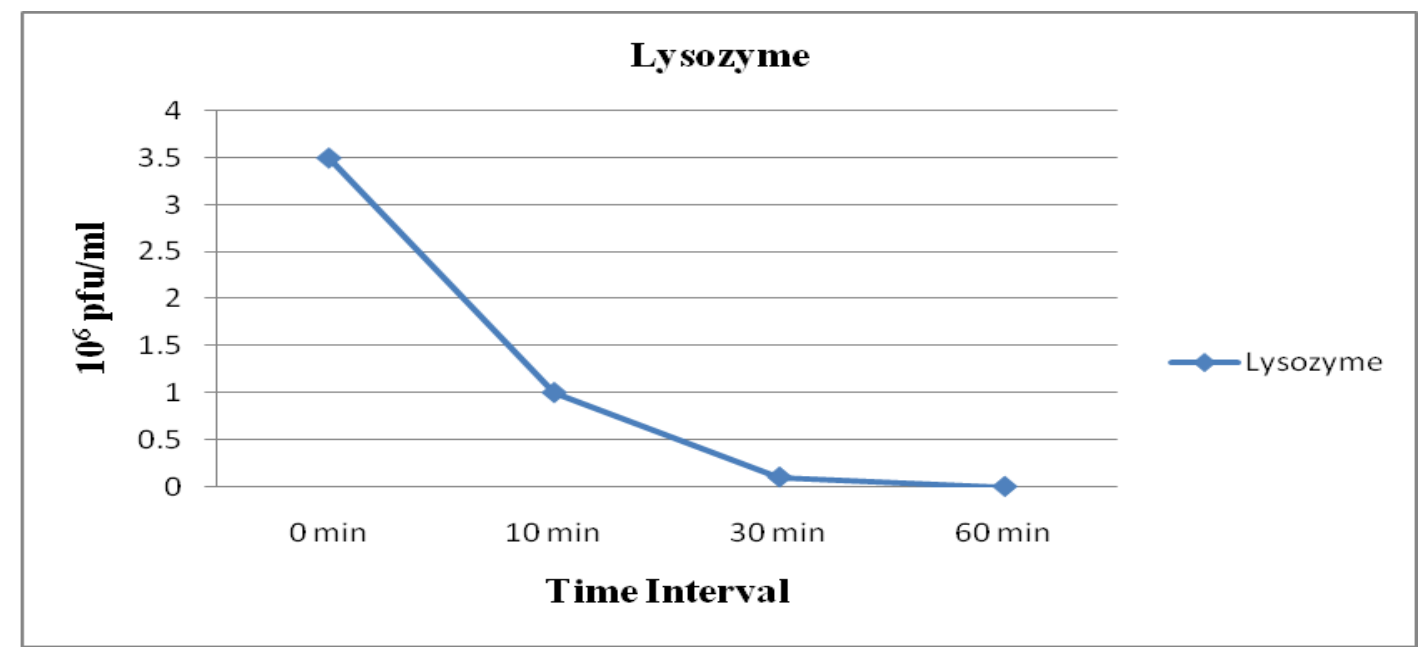


Fig.11 Effect of RNase on phage

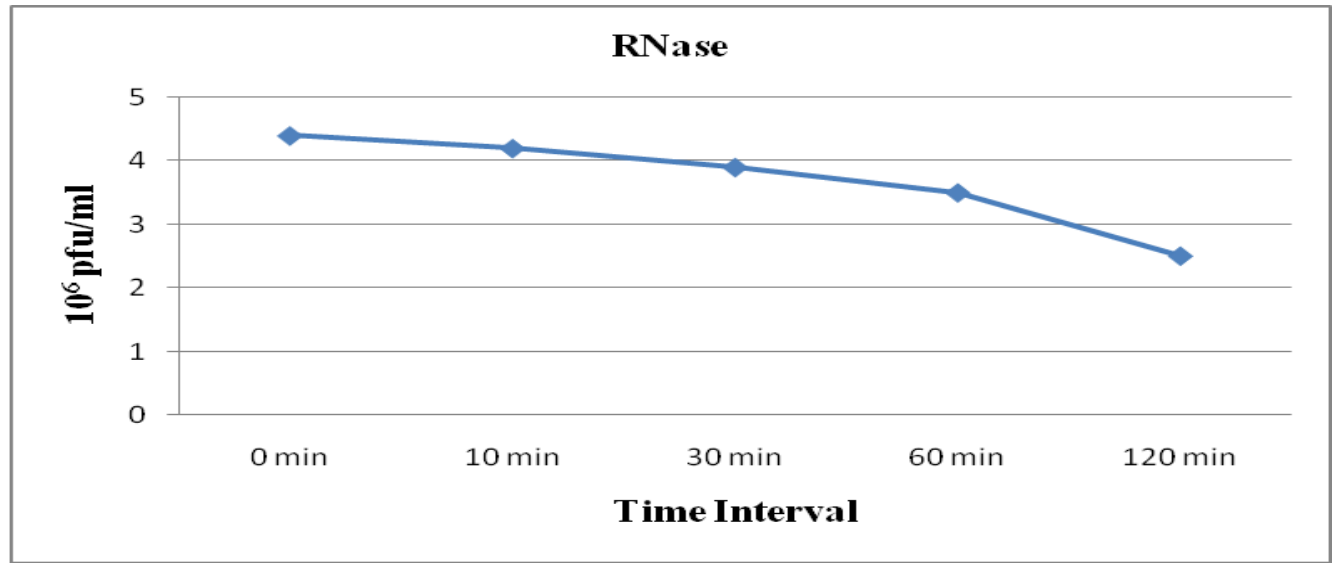

Rigby et al., (1989) reported that Nepean (Np) was morphologically identical to the other brucellaphages, with an icosahedral head (diameter 50-65 nm) and short tail (length 15$20 \mathrm{~nm})$.

Our observations on lytic ability of phage were similar to those of Chachra et al., (2012) and Pandey et al., (2013) and who had reported that their brucellaphage did not lyse any of the heterologous bacterial species tested viz. Staphylococcus aureus, Streptococcus species, E. coli, P. multocida, Pseudomonas species and Salmonella Dublin. Morris and Corbel (1973) have reported that the isolated Weybridge phage was lytic for smooth $B$. abortus biotypes $(1,2$, 3, 4, 5, 6, 7 and 9), B. suis biotypes (1, 2, 3 and 4 ), and $B$. neotomae cultures but there was no lysis of B. canis, B. melitensis and B. ovis strains. Pandey et al., (2013) had reported clear plaques of brucellaphage of variable size (0.1 to $3 \mathrm{~mm}$ ). Morris et al., (1973) observed clear plaques of phage A422 of 0.1 to $2.0 \mathrm{~mm}$ diameter whereas the plaques of S708 and M51 were of two types i.e. small, turbid plaques, 0.1 to $0.5 \mathrm{~mm}$ in diameter, and large, clear plaques, 0.5 to $2.5 \mathrm{~mm}$ in diameter. McDuff et al., (1961) had reported that $18 \%$ brucellaphages were inactivated at $60^{\circ} \mathrm{C}$ and there was $100 \%$ inactivation at $70^{\circ} \mathrm{C}$ within $60 \mathrm{~min}$. Pandey et al., (2013) have also reported that at $40^{\circ} \mathrm{C}$ the brucellaphage titre gradually decreased from $1340 \mathrm{pfu} / \mathrm{ml}$ to110 $\mathrm{pfu} / \mathrm{ml}$ within $3 \mathrm{~h}$ and treatment at $60^{\circ} \mathrm{C}$ completely inactivated the phage within 10 min. Our observations were similar to the observations of McDuff et al., (1961) who reported that there was no loss in phage titre in broth at $\mathrm{pH}$ values of 6.2 to 8.1 whereas, at $\mathrm{pH} 3.1$ there was complete $(100 \%)$ inactivation, $56 \%$ at $\mathrm{pH} 4.1,24 \%$ at $\mathrm{pH} 5.0$, $35 \%$ at $\mathrm{pH} 9.0$ and $42 \%$ inactivation at $\mathrm{pH} 9.9$, respectively. Pandey et al., (2013) reported that treatment at $\mathrm{pH} 2$ completely inactivated the phage within $3 \mathrm{~h}$, whereas the phage titre gradually decreased to zero within $24 \mathrm{~h}$ at $\mathrm{pH} 4$. At $\mathrm{pH} 6$, there was only $38.9 \%$ decrease in the phage titre after $48 \mathrm{~h}$ of treatment. The phage remained stable at $\mathrm{pH} \quad 8$ with $75.31 \%$ survivability after $48 \mathrm{~h}$ treatment. At $\mathrm{pH} 10$, the phage titre gradually decreased to $0.31 \%$ within 48 h. Pandey et al., (2013) have also reported that direct sunlight gradually decreases the phage titre and within $3 \mathrm{~h}$ brucellaphage is reduced by $93.99 \%$ and exposure to UV rays inactivated the phage completely within $3 \mathrm{~min}$.

McDuff et al., (1961) had reported that there was $99 \%$ inactivation of phage by $10 \%$ chloroform within 5 min. Pandey et al., (2013) had also reported the complete inactivation within $5 \mathrm{~min}$. of exposure of phage to $10 \%$ chloroform, within $15 \mathrm{~min}$. of SDS treatment and within 1 hour with lysozyme treatment. Morris et al., (1973) had also reported no detectable effect on phage titre after RNase treatment for $90 \mathrm{~min}$. Pandey et al., (2013) had reported that phage remains almost stable up to $3 \mathrm{~h}$ after treatment with RNase. 


\section{Potential of phage for therapy}

The new phage reported here is a broad acting lytic brucellaphage and can be evaluated in vivo for effective therapy of bovine brucellosis.

We have isolated a broad acting lytic brucellaphage. It was a tailed phage with icosahedral head. The phage belonged to the order Caudovirales and family Siphoviridae.

\section{Conflict of interest}

The authors declare that there is no conflict of interest.

\section{References}

Ackermann H W. 2007. 5500 Phages examined in the electron microscope. Arch. Virol. 152: 277-43.

Adams M H. 1959. Bacteriophages. Interscience, New York.

Cai-Zhong Z, Hong-Yan X, Jing H, Bu-Yun C, Dong-Ri P, Ya-Fei L, Hai J, Qian R, XiangYu M, Ya-Ming C, Xia H, Hong-Yan Z and Lan-Yu L. 2009. Molecular characterization of $\mathrm{Tb}$, a new approach for an ancient brucellaphage. Int. J. Mol. Sci. 10: 2999-11.

Calderone J G and Pickett M J. 1965. Characterization of Brucellaphages. J. Gen. Microbiol., 39, 1-10.

Chachra D, Kaur H, Chandra M and Saxena H M. 2012. Isolation, electron microscopy and physicochemical characterization of a brucellaphage against $B$. abortus Vaccine Strain S19. Internet J. Microbiol. 10(2).

Chilamban C, Rawat M and Somvanshi R. 2004. Pre-clinical studies on therapy of $S$. aureus mastitis by bacteriophage in mice model. Ind. J Comp. Microbiol. Immunol. Infect. Dis. 25: 98-103.

Gupta, V and Saxena H M (2017) Isolation, biochemical characterization and PCR confirmation of antibiotic resistant Brucella abortus from cattle and buffaloes in Punjab state of India. Res. Environ. Life Sci. 10(8) 718-723.

Mathur B G, Amarnath S K and Shinde R S. 2007. Review of clinical and laboratory features of human brucellosis. Ind. J. Med. Microbiol. 25: 188-02.

McDuff C R, Jones L M and Wilson J B. 1961.Characteristics of brucellaphages. $J$. Bacteriol. 83: 324-29.

Mohan A, Saxena H M, Malhotra P (2016) A comparison of titers of anti-Brucella antibodies of naturally infected and healthy vaccinated cattle by standard tube agglutination test, microtiter plate agglutination test, indirect hemagglutination assay, and indirect enzyme-linked immune sorbent assay. Vet. World 9(7): 717-722

Morris J A and Corbel M J. 1973. Properties of a new phage lytic for Brucella suis. J. Gen. Virol. 21: 539-54.

Morris J A, Corbel M J and Phillip J I H. 1973. Characterization of three phages lytic for Brucella species. J. Gen. Virol. 20: 63-73.

Pandey S, Chachra D, Chandra M and Saxena H M. 2013.Protein profiling and physicochemical characterization of an isolated phage against Brucella abortus strain 19. Afr. J. Microbiol. Res. 7(14):1233-38.

Rigby C E, Cerqueira-Campos M L, Kelly H A and Surujballi O P. 1989. Properties and partial genetic characterization of Nepean Phage and other lytic phages of Brucella Species. Canad. J. Vet. Res. 53(3): 319-25.

Romero C, Gamazo C, Pardo M and Lopez-Goni I. 1995. Specific detection of Brucella DNA by PCR. J. Clin. Microbiol. 33(3): 615-17.

Sambrook, J. and Russell, D.W. (2001). Molecular Cloning: A Laboratory Manual; Coldspring Harbor Laboratory Press NewYork, USA.

\section{How to cite this article:}

Vimlesh Gupta and Hari Mohan Saxena. 2017. Isolation and Characterization of BpL1, a Broad Acting Lytic Bacteriophage against Brucella. Int.J.Curr.Microbiol.App.Sci. 6(11): 2486-2496. doi: https://doi.org/10.20546/ijcmas.2017.611.292 